\title{
LA TRADICIÓN MANUSCRITA EN EL POEMA DE MIO CID A LA LUZ DE UNA INTERPOLACIÓN (vv. 404-412)
}

\section{Livinak}

Innumerables son las deudas que todo amante de la lengua o la literatura española guarda con don Ramón Menéndez Pidal. Una tengo en especial, de carácter casi anecdótico, que traigo a cuento: notando la marcada incongruencia entre los rasgos veristas y los poéticos presentes en el Poema de mio Cidi (en adelante, $P M C$ ) sugería el maestro la mano sucesiva de dos poetas juglares en su factura, y proponía seguir en su identificación un método poco académico quizás, pero idóneo: "Como en una novela policíaca, trataremos de apurar, cuanto más podamos, la parte que en la constitución del poema, tal como hoy lo tenemos, corresponde a cada uno de estos dos poetas".

"Como en una novela policíaca" es una frase cuyos ecos se escuchan en la investigación nilológica y en la crítica textual más habitualmente de lo que pensamos -y de lo que abiertamente confesamos. Las azarosas condiciones de transmisión y la escasa cantidad de manuscritos conservados, orillan muy frecuentemente a ello; en el territorio de la épica, específicamente, el panorama no es mejor: la falta total de fuentes primarias y la fragmentariedad de las evidencias conservadas, ya más próximas -apenas unos 5000 versos, entre la versión conservada del $P M C$, las Mocedades de Rodrigo y el fragmento del Cantar de Roncesvalles ${ }^{2}$-, ya más distantes - las versiones prosísticas, las versiones rimadas que nos conservan los romances, una versión en cuadernavía del Poema de Fernán González- hacen del quehacer fi-

1 Menéndez Pidal 1963, p. 144.

${ }^{2}$ SMith, p. 21. (Cuando la referencia proviene de una de las ediciones del $P M C$, se indica únicamente el nombre del editor, sin fecha.) 
lológico una verdadera "novela policíaca", en la que los cabos por atar no son pocos.

Nuestro manuscrito de Vivar' es una de estas fuentes que - si bien tardía (mediados del sigio xIV)- ha merecido la ma yor confianza, suponiéndola parte de una tradición textual conservadora"; su paso por una larga transmisión manuscrita es, sin embargo, patente ${ }^{5}$. En esta linea se encauza el interés del presente estudio: determinar, en la medida de lo posible y desde el apoyo que nos brinda el códice conservado, los estados factibles de transmisión ranuscrita a que ha estado sujeto nuestro poema. El trabajo tiene como núcleo un episodio en especial - los vv. 404 412, que supongo interpolados-w, cuya importan-

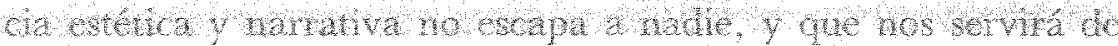
ayuda para bosqugar algunas condustenes a proposito de composición total del PMC. Germán Orduna, uno de los primeros en advertir la importancia de esta "pesquisa policiaca", escribía en un articulo reciente:

Es posible conjeturar que ya la copia de Per Abbat manifestaba un proceso de tradicionalidad escrita. Discernir cuáles son los elementos de esa primitiva etapa de transmisión manuscrita que Per Abbat recibió ya incorporados en su labor de copia sería labor improba, pero de resultados quizá sorprendentes 6 .

Queda pues, lo siguiente, como un segmento inicial de tal labor, en aras de la "novela policiaca" que los estudios cidianos tiener todavía por delante.

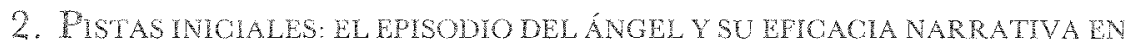
EL POEMA DE MIO CID

1. $9 \mathrm{r}$.

Y le echaua myo cid delpues à fue çenado

v. 405 wheol p'lo dulce tä bié fe adurmio

El angel gabriel a el vino en Reino

Caualgad ça el bue campeador ca ruq

${ }^{3}$ Actualmente en la Biblioteca Nacional de Madrid, bajo la signatura Vitra. 7-17.

4 Menéndez Pidal, pp. 32-33; López Estrada 1982, p. 21

${ }^{5}$ Menéndez Pidal, pp. 29-31; Orduna 1989, pp. 8-11.

6 ORduna 1989, p. 11. 
En tä buen punto caualgo varon

Mientra quilo'eredes bie fe fara lo to

v. 410 Qando deperto el sid la cara fe ligo

Sinaua la cara a dios \& acomendo

Mucho era pagado del herno a a binado'.

El episodio del sueño del Cid ( $v v .404-412)$ forma una tirada imperfecta y está dividido en dos partes: un enmarque narrativo (comice) y el mensaje en estilo directo (sin verbum dicendis) del ángel Gabriel. El primero se encuentra interrumpido por el mensaje (vy. 407-409), y sus dos partes (w. 404-406, 410-412) corresponden al registro de las circunstancias que rodean la aparición. Las tres partes están eguubradas en cuanto al número de versos (tres en cada una), lo cual pudiera no carecer de una intencion simbolica?.

El fragmento relata un momento significativo del destierro: la aparición del ángel Gabriel durante la última noche pasada en Castilla. Esta aparición ocurre luego de partir con desazón de Cardeña y de dos días de intenso trayecto, pormenorizado en

7 La transcripción paleográfica está hecha sobre los vv. $404-412$ (î. 9r) del ms. Vitra. $7-17$ de la Biblioteca Nacional de Madrid; he recurrido para ello a la cdición facsimilar de 1961. El manuscrito resulta muy legible en esta parte, por lo cual no he necesitado acudir a otras ediciones lacsimilares; he intentado inútimente consultar, sin embargo, la paleografia realizada por Ruiz Asencio para la edición que recientemente publicó el $H$. Ayuntamicnto de Burgos (1982), pero me ha sido imposible el acceso al inico jemplar disponible en México - hasta donde sé-- para si consulta (Bibloteca de El Colegio de México, 861.12/C 568 pa/1982). El pasaje se desarrolla a lo largo de unos pocos versos (apenas 9) en un folio conservado de los reactivos, pulcro y muy legible (salvo en la parte superior derecha, que presenta un oscurecimiento y una arruga que afectan mínimamente los tres primeros versos). Mi paleografia no se separa en mucho de la realizada ya por Menéndez PIDAl (pp. 921-922), salvo que he preferido seguir el texto con fidelidad (por ello respeto las abreviaturas, indicadas por una tide, y sacrifico cualquier marca de puntuacón, por no habcr tal en el manuscrito). Cito, en adelante y para faclltar la consulta de las referencias, por la edición española do Tan Michael consignada en la bibliografia, salvo indicación.

a A propósito, DAmaso Alonso 1973, pp. $109 \mathrm{~m} 11$.

9 Recuérdese, por ejemplo, la conocida estrofa de Berceo en Sto. Dom. que dice: "Cono son tres personas c una Deidad, / que sean tres los libros, una certanedad, / los libros signifiquen la santa Trinidad/la materia ungada, la simple Deidad' (estr. 534). Para otros ejemplos literarios, pueden verse Jaceues Joset en $L B A$, pp. xy-xxi y, muy especialmente, Jesús Gañas en Alex, pp. $42-49$. 
apenas doce versos (vv. 391-403), esto último no sin justificación (el vv. 392 recuerda que cerca viene el plazo por el rreino quitar). En la primera jornada de camino, el Cid y sus mesnadas llegan hasta Espinazo de $\mathrm{Can}^{10}$, donde pasan la noche; durante la segunda jornada atraviesan Alcubilla del Marqués (tratada injustificadamente como frontera del territorio cristiano) $)^{11}$, siguen luego por la Calzada de Quinea ${ }^{12}$ para cruzar el Duero por $\mathrm{Na}$ va de Palos $^{13}$, un poco al sur de Alcubilla; esa noche, el Cid y sus vasallos pernoctan en la Figueruela ${ }^{14}$. Luego del mensaje del ángel Gabriel, acogido con no poca alegría por el Cid (v. 412), este último se dirige a la sierra de Miedes, frontera de Castilla en los países musulmanes, para iniciar sin tregua la toma de Casteich

Esta visio del Cid, tal y como la hemos restringido a los vv. 404-412, llama la atención por su falta de correspondencias similares en el poema; el autor, como hace notar J. Horrent $t^{15}$, resulta poco afecto a las intervenciones sobrenaturales - a diferencia, por ejemplo, del $P F G z^{16}$ o de la Chanson de Roland ${ }^{17}$. El poema, tal y como se nos ha conservado, presenta esta escena aislada de toda otra intervención divina, y es esta novedad en la estructura narrativa de la obra una primera pista que nos indica con pelos y señales la inminencia del problema.

Pese a ello, la importancia del sueño de Rodrigo no parece estar a discusión: para Salinas, "la llamada del ángel es la más certera de las vocaciones", aquella que inicia la transformación de los duelos en gozos, por obra de sus aspectos ${ }^{18}$; Mérimée ha-

10 Michael lo identifica situado posiblemente en la Sierra al sur de Silos, donde varios parajes pudieron haber tenido este topónimo de orden muy popular (Michael, p. 106, n.).

${ }^{11} \mathrm{Al}$ este de San Esteban, en la ribera norte del Duero; sobre el título de frontera, véase MichaeL, p. 107, n.; Russell 1978, pp. 171-172.

${ }^{12}$ Michael la identifica con "la antigua calzada romana que iba del N. E. al S. O. desde Osma hasta Tiermes" (Michael, p. 108, n.).

${ }^{13}$ La actual Navapalos a orillas del Duero.

${ }^{14}$ Que según Michael, "podría haber estado dentro de los 4 kms. entre Navapalos y Fresno de Caracena" (Michael, p. 108, n.); la mención, junto con aquélla de Espinazo de Can, pertenecen a lo que J. Horrent denominó microtoponimia (HORRENT 1973, pp. 315-319).

${ }^{15}$ Horrent, pp. xx-xxi.

${ }^{16}$ Estrs. 236 ss., 402 ss., 411 ss., 424 ss., 550 ss.

17 Por ejemplo, vv. 717-724, 725-736, 2525-2554, 2555-2569, 39914001.

18 Salinas 1958 , pp. 33-34. 
ce notar la singularidad de este hecho sobrenatural, que "encore n'est-ce qu'un songe, et peut-être même une imitation de l'épopée française" 19 ; para Casalduero, "el ángel le augura un éxito continuo" que no requiere ser identifícado como ficción o realidad: forma, al fin de cuentas, parte de la realidad épica $a^{20}$; para Chasca, el episodio resulta verosímil cuando apunta: "el arcángel se le apareció en sueños... como hubiera podido aparecérsele a cualquiera" ${ }^{21}$. Para N. P. Dunn se trata de la culminación de varios preliminares "... of the technique of fanning the spark of hope in the darkness of adversity"22; Horrent comparte esta visión, proponiendo la factibilidad del episodio ${ }^{23}$; para Russell, el episodio es garantía que augura los éxitos futuros del Cid tanto como una respuesta favorable de Dios a la oración hecha versos antes por Ximena24; Garci-Gómez lo considera un "augurio" que acompaña el "nacimiento de la gesta" del Cid como héroe épico ${ }^{25}$.

En efecto, el mensaje del ángel Gabriel en el sueño del Cid representa una garantía de los éxitos futuros para el Campeador, pero aún algo molesta cuando comparamos éste con relatos análogos - sean o no sus posibles fuentes-, ya provenientes de la tradición latina ${ }^{26}$, ya venidos de la francesa ${ }^{27}$ : significa una garantía cuyo valor no deja de parecer demasiado amplio.

¿Cuál es la eficacia narrativa que podemos realmente atribuir al episodio en este punto del relato? ¿Qué información suma a lo que como lectores o auditores ya sabemos? El mensaje del ángel es emotivo y explícito a la par, pero digámoslo también: explícito con lo que ya sabemos. Como Montgomery explica, lo que importa no es la información, sino ". . . the quality of the experience" 28 .

19 Mérimée [1915], p. 5.

${ }^{20}$ Casalduero 1967 , p. 53.

${ }^{21}$ Chasca 1972 , p. 136.

22 Dunn 1962, p. 350.

${ }^{23}$ Horrent, p. xxi.

24 Russell 1978, p. 118; también Smith, p. 75; Michael, p. 108, n.; MONTANER, p. 432, n.

${ }^{25}$ Garci-Gómez 1975, p. 281.

${ }^{26}$ Especialmente bíblicas: On 28,12-16; Mt 1,20-24, 2,13-14 (véase Montaner, p. 433 , n.).

27 Especialmente la Chanson, vv. 2525-2569 y 3993-4001 (véase Horrent 1973, pp. 372-373).

28 Montgomery 1977 , p. 97. 
Que el Cid cabalga o nace en tan buen punto, en tan buena ora, Io sabemos ya: como epíteto épico aparece con anterioridad en seis ocasiones ( $v v .71,202,245,266,294,379)^{29}$. La seguridad del retono al amor del rey y del ameglo de sus asuntos (bien se fará lo to v. 409) está anticipada desde los primeros momentos: en el discutido augurio del vuelo de los pájaros (vv. 11-12) ) $^{30}$ en el verso conjetural $14 \mathrm{~b}$ adosado por Menéndez Pidal ${ }^{31}$; Alvar Fánez augura: Aun todos estos duelos en gozo se tornaran (v. 381); el Cid promete doblar el sueldo a Martín Antolínez si vive (v. 80), mandar buenas donas e micas al altar de la Virgen, y cantar mill missas si la ventura le fuere conplida (vv. 221-225); igual promete, por cada marco extra que el abad don Sarcho dispense para el cudado de Xmena y de las hijas del Cic, pagar cuatro al monasterio (v 260); promete igual dobhe has perdidas do su soldada (w. 302303). El Campeador, seguro del restablecimiento de su honra, no sólo se contenta con hacer promesas a un plazo relativamente incierto: el contrato que establece con Raquel y Vidas tiene validez por un año (vv. 120-121 y 162); el mismo contrato se realiza con el abad don Sancho (v. 254). Todos estos índices que, según se ve, estarían adelantándose a la aparición del ángel como una suerte de motivos sobre el mismo tema, que no hacen sino anticipar el escueto comunicado: el restablecimiento de la honra y del peculio de Rodrigo. El valor que como mecanismo narrativo debían tener las palabras del ángel Gabriel al anunciar al Gid de la ventura próxima ("...mientra que visquiéredes bien se fará lo to" , v. 409) parece muy mermado a la ha de dichos índices.

Bl mensaje del ángel es redundante y lacónico; esto parece mucho más claro cuando lo comparamos con aigunos episodios análogos en la épica francesa y en liturgia latina en la Chanson, por ejemplo, la sola ocasión en que el ángel se hace presente por medio del discurso directo (vv. 3993-3998), to hace hablando a Carlomagno y describiendo la acción futura con lujo de deta$\operatorname{lles}^{32}$. Así en sus correspondientes bíblicos; en Mt, por ejemplo,

29 Sigo el registro de CHASCA 1972 , pp. $337-382$.

30 Véase a propósito Horrent 1973 , pp. $218-219$ y Garci-Gómez 1975, p. 59.

31 Verso que casi todos los editores rechazan; Montaner aduce tres objeciones, una de las cuales nos interesa: la atribución del verso es innecesaria por la redundancia que presenta frente a la aparición del ángel Gabriel (MoNTANER, p. 392, n.).

32 Recordamos el episodio "Seint Gabriel de part Deu li vint dire: / "Car" les, sumun les oz de tun emperie! / Par force iras en la tere de Bire, / 
la intervención del ángel Gabriel en el sueño de José33 se realiza por un discurso directo cuya intención primordial es un comunicado preciso, dicho con la llaneza más clara y una estricta circunscripción ${ }^{34}$.

No obstante la particularidad del episodio, podríamos proponer una especie de hilo narrativo que encadena el sueño del Cid con otros episodios, significativos todos ellos por los motivos religiosos que presentan $y$ que, vistos como un todo, toman sentido entonces por su reiteración ${ }^{35}$. La mera presencia de dichos

Reis Vivien si succuras en Imphe, / A la citet que paim unt asise: / I chrestien re redement e crient." "Chamon. v. 3994-3998).

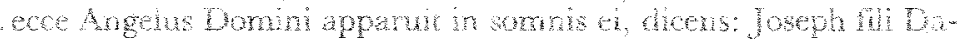
Wa, nol there acciper Manum convgem tum: quod enim in ea natum est de Spiritu sancto est. // Fariet atrem filum: et vocabs nomer ejus JESUM: ipse enim salvum faciet popuhm sum a pecatis cortum. // Hoc attem totum factum est, adimpleretur quod dictum est a Domino per Prophetam dicentem: // Ecce virgo in utero habebit, et pariet flium: et vocabunt nomen ejus Emmanuel, quod est interpretatum Nobiscum Deus" (Mt 1,20-23).

${ }^{34}$ Los sueños, en los ejemplos anteriores, responden a situaciones concretas con lujo de detalles, a diferencia del ángel cidiano: un imperativo, "cavalgad', que como apunta SALINAS (1958, p. 34), es sumamente preciso en la condición del Cid, pero que no dice nada cuando lo comparamos con los pormenores que le escuchamos a Gabriel en la Chanson: álzate en armas (sumun les oz, v. 3994), en la tierra de Bire (en la tere de Bire, 3995), ayudarás al rey Vivian, en Imphe (Reis Vivian si succures en Imphe, $y .3996$ ), porque aht tienexs asiento los paganos (paient unt asise, v. 3997), porque la cristiandad te grita y te reclama (Li chrestien te recleimeni e crient, v, 3998). En el caso que nos ocupa, un augurio nada más se deja escuchar por boca del ángel: bien se fara lo to. (v. 409) ¿Qué significado tiere lo to "tus asuntos irán bien"? El pasaje del ángel en $\mathrm{Mt}$, antes citado, responde específicamente a un plan narrativo, que no sólo toma en consideración los elementos dados por el decurso de la obra misma (por ejemplo, ". . . noli timere accipere Mariam conjugem tuam. ..", responde a la duda que nace unos versículos atrás: ". . antequam convenirent, inventa est in utero habens de Spiritu sancto...", Mt 1,18-20), sino también episodios del Antiguo Testamento (" . . Hoc autem totum pactum est, ut adimpleretur quod dictum est a Domino per Prophetam dicentem...', etc.). La relación que guarda el episodio con la estructura total del $P M C$ resulta pobre en extremo, y en tanto recurso narrativo, creo que no obedece a los propósitos esenciales que cumplen este tipo de apariciones en otros textos.

${ }^{35} \mathrm{El}$ antecedente inmediato puede encontrarse en las palabras de Aivar Fáñez, apenas unos pocos versos atrás (vv. 379-382): "Dios que nos dio las almas conseio nos dará" (v. 382) dice anticipando la aparición angélica. Éstas, que narrativamente se estorban como una suerte de reiteración del motivo, adelantándose Alvar a la aparición del ángel, se leerían entonces como preparación de la aparición divina. La oración de Ximena (vv. 330-365) parece, a la luz de la narración, otro antecedente importante: el mensaje del ángel 
motivos religiosos, sin embargo, no permitiría suponer un plan organizado dentro de la estructura general del poema ${ }^{36}$ : apenas 3 versos para la rogatoria del Cid (vv. 52-54); 9 versos para la segunda (vv. 217-225), 35 versos para la oración de Ximena (vv. 330365). El sueño del Cid no parece caracterizarse por su extensión, pobre al compararla con estos hipotéticos episodios preparatorios, ordenados en forma de una curva ascendente. Aun cuando sabemos que el PMC no se caracteriza por guardar la proporción en cuanto a la distribución formal de sus episodios (bastaría revisar, por ejemplo la extensión de sus distintas tiradas), una respuesta de 3 líneas apenas, desentona con los antecedentes que hemos propuesto.

\section{UN TESTICO ORIGWALDAD DEL WPISOBIO MNTERPOLADO $3 \%$}

El episodio se sitúa en las ediciones críticas en la tir. 19 y parte de la tir. 20. Comienza de manera imperfecta y sorpresiva en un

representa una respuesta a la sentida plegaria de la mujer del Cid (Russel 1978 , p. 118). Ambos episodios están formulados sobre la base de ciertos índices característicos de los personajes que nos han sido dados con anterioridad: la devoción del Cid nos ha sido anticipada, primero bajo la forma de una invocación directa, al estilo de las lamentaciones de Job (vv. 8-9), luego bajo la forma de un creyente fervoroso que dos veces se detiene a orar delante de la catedral de Burgos, Santa María (vv. 52-54 y 215-225); a doña Ximena podemos encontrarla rezando los maitines (vv. 239-241).

$36 \mathrm{Y}$ en caso de serlo, parece restringido al primer Cantar, en cuyo caso bien podría tratarse de interpolaciones posteriores: ya el carácter fomulario de la oración de Ximena hacía dudar a Menéndez Pidal de su pertenencia al cuerpo originario del poema, que alargaba la tirada 18 de forma inusual (ME. NÉndez Pidal 1963, p. 143).

37 Por 'interpolación' se entiende el pasaje aislable que podemos definir como el excedente, cambio o innovación que presenta una copia respecto al códice modelo; éste, incluido ahí con una intención precisa, no atenta necesariamente contra la conformación de la obra. Sigo a RoNCAGLIA 1975, p. 126; LÁzaro Carreter 1973, p. 244. La marcada tendencia crítica a suponer el PMC producto de refundiciones juglarescas - esto, muy especiamente, luego del conocido artículo de "Dos poetas en el Cantar de Mio Cid" (Menéndez PIDAL 1963, pp. 109-162)-, hacen que en ocasiones los términos 'interpolación' y 'refundición' aparezcan confundidos (véase a modo de ejemplo ALBerto BlecUa 1983, p. 111, n. 1). La distinción es de matiz, pero tiene consecuencias importantes: la refundición de textos no aparece supeditada a un ambiente; igual se refundieron textos de carácter eminentemente oral -y ahí tenemos como ejemplo la continuación de las canciones de gesta en los romanceros populares - que textos de carácter culto y, por tanto, escrito - pienso en las dos versiones manuscritas en las que se nos ha conservado el 
verso sin correspondencia con las asonancias inmediatas (v. 404, con asonante $\left.-a^{\prime}-0\right)$, colocado normalmente en la tir. 19; por el sentido del verso, resulta obvia su pertenencia a dicha tirada. Las enmiendas tocan sólo al asonante: Menéndez Pidal corrige por -ó (. . después que fo de noch, v. 404); Smith separa el v. 404 de la tir. 18 con asonante en $-a^{\prime}(e)$ y de la tir. 19 con asonante dominante en -ón ${ }^{38}$; Michael, Garci-Gómez y Bustos aceptan la solución del manuscrito (. . después que fue çenado, v. 404); Horrent y Cátedra enmiendan (... después que [çenado fo], v. 404); Montaner enmienda (...después que cenado fue, v. 404), siguiendo a Bello.

El término de la tir. 19 varía en cada editor: así, Menéndez Pidal termina la tir. 19 en el v. $410 ; 411$ y 412 los adosa a la tir. 20 uniformando los asonantes en -4 (. . se fo aconendar, v. 111 ; que soñado a, v. 412); Smith termina la tir. 19 en el v. $411 \mathrm{y}$ adosa el v. 412 a la tir. 20, separándola por un renglón y sin corregir el asonante; Michael considera el fragmento transcrito como una unidad: reúne los vv. 404-412 en la tir. 19; GarciGómez inicia la tir. 20 con el v. 412 sin mayor alteración; Horrent inicia también la tir. 20 con el v. 412, cambiando el asonante ( . . del sueño que [soñado a], v. 412); Bustos sigue a Menéndez Pidal; Cátedra sigue a Michael, sosteniendo la tir. 19 hasta el v. 412, con enmiendas de este último ( . . del sueño que [soñó], v. 412); Montaner resuelve de acuerdo con Horrent.

La úrada se continúa con asonancia dominante en -ó, salvo en el caso del v. 406, que se resuelve en sueño. Menéndez Pidal enmienda (. . a el vino en [visión], v. 406); es seguido por Smith, Horrent y Cátedra en su corrección; Michael, Garci-Gómez, Bustos y Montaner respetan la solución del manuscrito.

El episodio, como se advierte, es especialmente problemático por lo que respecta a la extensión precisa que abarcaría la tirada, si bien podemos darnos cuenta luego de una lectura detenida de la validez semántica y gramatical que tiene la restricción de los vv. 404-41239.

Libro de Alexandre, ambas con carácter acentuadamente dialectal. La interpolación, por el contrario, es un fenómeno exclusivo de una tradición escrita y conservadora.

${ }^{38}$ Respecto a esta particularidad editorial del trabajo de Smith (repeti$\mathrm{da}$, por ejemplo, en los vv. 174 y 412), comenta éste de los versos sin correspondencia que posiblemente sean " ... más que error del copista, un sistema quizá experimental de 'suma y sigue'" (Sмith, p. 49; amplía en SMith 1979 , pp. 38-39 y n.).

39 Atendiendo a ello, Michael y Cátedra unifican el episodio con la ti- 
El marco que circunscribe nuestro episodio, sin embargo, me parece un parámetro más seguro para determinar el espacio al que podemos entonces ajustar el fragmento interpolado: las dos secuencias camineras inmediatas anteriores (vv. $391-395$ y vv. $394-403)^{40}$ terminan con fórmulas paralelas: grandes yentes se $l e$ acoien essa noch de todas partes, v. 395 y vánsele acogiendo yentes de todas partes, v. 403, verso inmediato al inicio de la tir. 19, y un indicio que permite comenzar formal y temáticamente una nueva tirada en ol $v$. 404, aun cuando la pertinencia en el asonante no lo justifique. Por lo que toca al final que podemos adjudicar al pasaje, la siguiente tirada inicia (v. 413 ) con una fómula paralela al principio de la segunda secuencia caminera (Ono dia mañ-

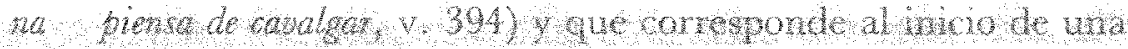
tercera secuencia de episodios paralelos (Otro him mama pientan de cavalgzt, v. A3), lo que nos indica la pertinencia de conchin el episodio en el v. 412. Estas frases formularias paralelas sirven para defmir el espacio donde el rragmento de los vv. $404-412$ habría sido interpolado:

1.

Soltaron las rriendas, piessan de andar, v. 391.

...

grandes yentes se le acoien essa noch de todas partes, v. 395.

2a secuencia:

Otro día mañana piensa de cavalgar, v. 394.

Wánsele acogindo yenter de walas pantes, v. 403.

[Episodio de los yy. $404-412 \ldots]$

3a secuencia:

Otro dia mañana piensan de cavalgar, v. 413.

. .

Los paralelos entre las secuencias $1^{\text {a }}$ y $2^{a}$, las coincidencias en el inicio de la $2^{a}$ secuencia y la $3^{a}$, el mantenimiento del asonante, $-\hat{a}-(e)$, durante las tiradas 18 (vv. 295-403) y $18^{\prime}$ (vv. 413415), nos indican el estado primitivo que guardaría el poema antes de la interpolación de este pasaje: empleando recursos anafóricos que servirian para dar un determinado énfasis narrativo a la apremiante partida, el Cid habría salido de Castilla en medio

rada; Montgomery, al analizar el episodio, lo considera completo a partir de los mismos parámetros que nosotros (MONTGOMERY 1977, p. 97).

${ }^{40}$ Seguimos la edición crítica de Michael, que invierte las líneas 394-395. 
más de una urgente retirada que de apariciones sobrenaturales. El episodio del ángel Gabriel, pues, se habría interpolado en el seno de estas series con un propósito contrario al que se advierte en el plan original de la estructura narrativa, retardando la acción primordial y que poca o ninguna relación debió haber tenido con visitaciones angélicas: salir de Castilla - apurados por la inminencia del plazo, que no deja de recordarse (vv. 309-310, $321,392,414)$.

Consideraciones temáticas y estructurales, sin embargo, no son las únicas que nos permiten tomar el pasaje como una interpolación posterior a una pretendida redacción original - quizá y muy posiblemente, anterior-: al intervenir nuestro copista en su modelo - - y ahora dejaremos un poco de lado el quién y el cuándo de la intervención, para retomarlo más adelante-, éste necesariamente se habría preocupado por mantener un estilo regular de acuerdo con el que hasta aquí se le había manifestado, pero con estilo no entendería como nosotros las particularidades escriturarias, retóricas, sintácticas, léxicas, etc., que reflejarían un habla propia - un idiolecto-, sino más claramente, los estilos determinados por una preceptiva retórica, y que tendrían que ver no con el autor primitivo del texto, sino con el género al que perteneciera éste. En general, hablar de estilo épico o lírico, prosaico o versal, no hubiera provocado sino confusiones, dadas las relaciones y contaminaciones que suelen con frecuencia darse en estos géneros; de ordinario, se pensaría en una división tripartita del estilo:

Sunt... tria genera, quae genera nos figuras appellamus, in quibus omnis oratio non uitiosa consumitur: unam' grauem, alteram mediocrem, tertiam extenuatam uocamus. Gravis est quae constat ex uerborum grauium leui et ornata constructione. Mediocris est quae constat ex humiliore neque tamen ex infima et peruulgatissima uerborum dignitate. Attenuata est quae demissa est usque ad usitatissimam puri consuetidinem sermonis (Herennius, IV, 11).

Dichos parámetros retóricos no bastaron, de todas formas, para suturar pulcramente la intervención en el modelo; por mucha solicitud y cuidado que el copista del poema cidiano tuviera al añadir estos versos, intentando mantener el estilo grave de su modelo, no pudo no quedar implícita la huella de un usus scribendi particular, novedoso y diferente respecto al que podemos concebir en el plan general de la obra. 
Ya desde el primer verso, el uso léxico de nuestro fragmento interpolado se muestra ciertamente innovador: la forma se echava es única en el sentido que comporta de "acostarse"; regularmente se prefiere el uso de yazer para indicar la acción de "dormir" o "pasar la noche" (por ejemplo: vv. 72, 393, 2635, 2702, 2869), " "permanecer" (por ejemplo: vv. 437 [+en selada], 573, 1209); y también, con cierta regularidad, podemos encontrar posar en el sentido de "pasar la noche" "41 (por ejemplo: vv. 402, 415, 428, etc.) o de "acampar" (vv. 56, 553, etc.). La forma se echava en el poema existe siempre con otras connotaciones: en el sentido de "arrodillarse" (por ejemplo: vv. 327, 1594) o de "ponerse en" (por ejemplo: vv. $436[+$ en celada], 1203). Yazer, dormir y echarse, ya para tiempos de Alfonso el Sabio han dejado de ser acciones sinónimas; así, por ejemplo, se las enumera en estos términos: "Jazer e echarse sabia muy apuestamiente e en buen contenente, e dormir..." (Setenario, p. 12).

Como ésta, muchas otras formas léxicas y sintácticas resultan igualmente innovadoras respecto al usus scribendi que persiste en el poema. Otro caso también interesante es el de fue çenado: si bien lexicalmente aparece el sust. ̧ena (vv. 1531, 2883), como participio pasado resulta ser una forma única. En el poema se prefiere con regularidad expresar la acción de comer, cenar o prepararse para la comida con el auxilio de adobar (+ compl.); por ejemplo: vv. 249 (+ conducho), 1017 (+ grant cozina), 2064 $(+$ cozina $)$, etc. Igualmente novedoso resulta que para este hemistiquio se prefiera un nexo temporal (después que) que no es de uso generalizado en el corpus del poema y que se encuentra con cierta regularidad sólo en el primer hemistiquio (vv. 884, 1116, etc.).

Sueño es una forma única que se repite con insistencia en el pasaje interpolado: refiriéndose, ya al 'acto de dormir' (vv. 405, 406), ya a la 'representación de sucesos durante el sueño' (v. 412 , con una derivación $)^{42}$.

Sueño (v. 405), en su primera acepción de 'tomar sueño', es una forma también particular; un suenol' priso se puede documentar con posterioridad en Berceo ("fue le de fiera guysa el suenno apesgando, / apremió la cabeça, fuesse adormjdando...", San

${ }^{41}$ Así lo prefiere, por ejemplo, la prosificación de la $P C G$, en que se lee: "... et fue posar a la figueruela...".

$42 \mathrm{El}$ uso del vocablo en sus dos acepciones se nos presenta indiferencia do desde épocas muy tempranas (CDECH, t. 5, p. 327). 
Millán,10 cd"3; también "...vn suenno muy sabrroso al conde fue tomando..." $P F G z, 402$ a) y en usos léxicos de la latinidad clásica (así, por ejemplo, “... somnus complexus est...", Somnium Scipionis, I).

Sueño (v. 407), enmendada por casi todos sus editores en visión, según se lee en la $P C G$ (...et fue posar a la figueruela, 524.b.19), para restablecer el asonante. La forma [venir]en sueño parece, muy probablemente, un calco de la latinidad clásica (". . visus in somnis...", “. . videre in somnis...", etc., $D e$ divinatione, I, XXII ss.) o del léxico escriturario, donde también resulta muy abundante ("... apparint in somnis...", Mt 1,20; "... admonitus in somnis...", Mt 2,22; también Mt 2,12, $2,13,3,19$ : Gn $28,12,31,24)$.

La figura sueño que a soñado $(v .412)$ retrata de manera fiel un uso retórico de mucho auge en la literatura latina medieval, rápidamente implementado por las nacientes literaturas nacionales: la adnominatio ${ }^{44}$. En el verso se hace una derivación de sueño cambiando la desinencia de la palabra, tercera categoría de esta figura retórica que conocía el Herennius: "Tertium genus est quod uersatur in cassum commutatione aut unios aut plurimum nominum..." (IV, 30).

Su empleo, aunque de gran vitalidad ${ }^{45}$, suele ser restringido y poco variado; ya el Herennius, a propósito, recomendaba no excederse en él, pues, pese a su elegancia, no se le podía encontrar "... sine elaboratione et sumptione operae" $(4,31)$. Se conocen formas tanto en la latinidad clásica (" .. somnium quod noctu hac somniaui", Miles gloriosus, v. 381; también v. 400) y litúrgica (". . et somniavi somnium nocte", Esdras $4,13,1)$, como en textos latinos de la época ("Si uera somnia forent que somnio...", Cancionero de Ripoll, 7[26], 1). Existen también múltiples ejemplos en textos literarios españoles posteriores: "Ensoñó esta duenna un sueño deseado...", Sta. Or., 188c; “...en el suenno que sonnara...", $P F G z, 411 \mathrm{a}$; "Ensonava esta noche entre sueños...", Sendebar, p. 126, etcétera.

${ }^{43}$ Crest. Esp. Med., p. 125.

${ }^{44}$ Véase Curtius 1975, pp. 392-394. El Herennius la define como una figura de dicción que se da " . . . curn ad idem uerbum et nomen acceditur cum mutatione uocum aut litterarum, ut ad res dissimiles similia uerba adcommodentur" (IV, 29).

${ }^{45}$ Von Richthofen cita varios ejemplos tomados de la Chanson y del propio PMC (VON Richthofen 1970, pp. 120-122). 
Dulçe, aplicado a un sustantivo, es un adjetivo que se emplea también sólo en esta ocasión - descartando, por supuesto, aquella otra en que cumple función de epíteto (so los mantos las espadas dulces e taiadores, v. 3077) para referirse al género de arma fabricada de hierro dulce ${ }^{16}$-; el adjetivo es de gran empleo en la Chanson (como epíteto de Francia: France dulce o dulce France, vv. $16,109,116,360,573,702,706$ et passim), y está documentado con prolijidad en Berceo (Milgr, 15a, 25a, 26b, 234d, 298c, 524b). En Berceo también (Mill., 11a), se puede ya documentar la frase sueño dulz relacionándola con la literatura de visiones: "Durmjó quanto Dios quiso suenno dulce e tenprado" ${ }^{7}$.

fe adumó existe ya en Berceo ('En la noche tercera yazié él

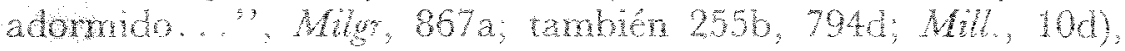
peno relacionado con el sueño o con visiones, sólo en dos ocasio. nes (Milgr., 867 a y Mill. 10d: "... apremió la cabeça, fuesse adormjdando. . "48).

En tan buen punio es la forma aproximativa de uno de los epítetos que se atribuyen al Cid con mayor frecuencia en el poema; éste, sin embargo, se registra con regularidad como el que en buena ora nascó ${ }^{49}$ o apocopado en buena por exigencias métricas (por ejemplo, v. 379). La forma buen punto, si bien es sinónimo, parece una manera inusual de referirse al Campeador, y las dos ocasiones en que se le emplea, su formulación resulta claramente anómala: en el v. 294, la inclusión de en buen punto bien podría tacharse de ser una interpolación que alarga el segundo hemistiquio. Menéndez Pidal, al refenirse a dicho verso en su edición critica la considera un glosado y la sustituye por su versión apocopada, en buena. La otra mención aparece en el v. 3068, refiriendose a Martín Muñoz: ". . e Martín Muñoz. que en buen punto naçió". Montaner hace notar ya lo "extraño", de esta adjudicación, a quien es conocido regularmente como "el que mandó a Mont Mayor" (v. 738), pero observando la condición de variante del epíteto astrológico (respecto a la mención de punto en vez de ora), decide no enmendarlo en su edición ${ }^{50}$. La formulación, como se ve, resulta atípica en todo caso.

46 Sobre el proceso de fabricación de las espadas dulces, véase MontaNER, pp. 441-442, n.

${ }_{47}$ Crest Esp. Med., p. 125.

48 Ibid., p. 125.

49 Versos 202, 245, 266, 663, 719, 787, 808, 935, 1008, 1053, 1114, 1237, 1584, 1730, 1834,1838, 2008, 2016, 2020, 2092, 2244 et passim.

${ }^{50}$ Montaner, p. 653; Hathaway 1974, pp. 312, n. 7. 
La cara se sanctigó es también innovadora: la convención en el poema regularmente relega el verbo y el complemento al segundo hemistiquio, dejando siempre libre el primero para referir el antecedente que caracteriza la acción de santiguarse en el resto del poema: "alzar la mano"; así, por ejemplo: alçó su mano diestra, la cara se sanctigua, v. 216; Alçó la mano diestra, el rrey se sanctigó, v. 1340; El rrey alçó la mano, la cara se sanctigó, v. 3508.

Esta particularidad formularia -que en el usus scribendi del poema parece ser muy rígida- existe también en la Chanson (vy, 340,2194, 2848) y en formas de la latinidad escrituraria ("Et extendens manus ad populum, benedixit ei...", Lev 9,22; ". .et elevatis manibus sis benedexit eis". Lc 24,50); el for" mulsmo, sin embargo, mantene cierta sotura ah donde se encuentran cstas fomas rigidas (Lievet sa main, fait sa bereigu, Chan. son, v. 2194) conviven también formulismos más flexibles como Sis beneist Carles de sa main destre (v. 3066) junto a una cantidad no pequeña de variantes que en mayor o menor grado se apartan de la fórmula inicial (vv. 1137, 1140, 1931, 2017, 2205, 2957, 3667, 3859). Documentado también en Berceo ("...desperté é signéme con mi mano alçada...", Sto. Dom., 244c) y con un uso un tanto sorprendente en el Libro de buen amor ("Alçó el león la mano por la mesa santiguar...", LBA, 86a).

Resulta de especial interés el glosado de carácter lexical que le sigue y liena el primer hemistiquio del verso siguiente $(v, 411)$. Sinaua la cara, amén de un cultismo ${ }^{51}$, es uno de los pocos glosados que existen en el poema; la otra ocasión en que la figura se repite corresponde al episodio de la oración de Ximena (...pasores te glorificaron, oviéronie a laudare, v. 335$)^{52}$.

Las otras fórmulas léxicas y sintácticas del episodio, pese a no ser tan francamente innovadoras, presentan siempre peculiaridades y matices con respecto al usus scribendi en el resto del poema.

El epíteto el buen Campeador no se repite con frecuencia; aparece, por ejemplo en el v. 236 con la adición de Cid (el buen Cid Campeador), pero es raro. La fómula completa, tal y como aparece en el verso (Gid, el buen Campeador), resulta extraña al estilo general del

51 Como una derivación conservadora de signare, que mantiene la "i" y que simplifica la consonante cuita "gn" en "n" -en lugar de "ñ", como hubiera sido la norma común- (Menéndez PIDAl, pp. 151 y 185 ).

52 El glosado culto de términos cotidianos y reconocidos en el habla popular se nos presenta como una evidencia del paso del poema por el tamiz de los scripioria monacales. 
texto; por lo regular mio Cid el Campeador ${ }^{53}$ o el Cid Campeador ${ }^{54}$.

La conexión causal ( $c a$ ) acompañada por el adverbio temporal (nunqua) sólo aparece otra vez en el v. 2347, al principio del verso; colocado al final del v. 407 no podemos pensar sino en un yerro de copista; éste, sin embargo, no deja de ser significativo: muy posiblemente esta interpolación haya estado escrita en un principio como glosado en prosa, quizá al margen de un manuscrito primitivo o al pie de éste. Esta hipótesis aclararía la vacilación en cuanto a los asonantes (vv. 404, 406, 412), y no sería extraña a los procedimientos naturales de glosado o enmiendas en el acto de la copia.

Varón, como sustantivo genérico, se emplea preferentemente cn forma plural (v. 16b, 313,2848, 3347, 3377), aparece en sin gular en la frase hablar a guisa de varón (vv. 1350, 3125, 3154, $3525 \mathrm{~b}$ - este último en plural-), que parece ser más bien un calco del francés ("Vait le ferir en guise de baron", Chanson, v. 1226; también vv. 1889, 1902, 3054) y por lo tanto, una frase tópica.

La forma mientra que visquiéredes aparece regularmente en el poema con el sentido de 'tener fortuna suficiente para vivir toda una vida' (vv. 158, 173, 2542), con el verbo vivir en modo subjuntivo.

En un principio, los paralelos con el v. 925 del poema y este v. 409 me preocuparon, pues podrían sugerir que me equivocaba en cuanto a suponer el episodio interpolado. Creo ahora, que se trata de un tópico del habla diaria, un localismo que se diría a la manera de un refrán o de un adagio popular. Esta suposición, aunque aventurada, tiene bases que no podemos rehusar: el cambio de persona en el discurso del ángel (que va del vos al tú), en apenas el mismo verso y sin suponer necesariamente la confusión de un copista al realizar la copia ${ }^{55}$, nos hace pensar que se recurriría aquí a una frase hecha. Se utiliza también en la Chanson (...tam cum vivet sis niés, v. $544 ;$. . tant cum vivet Roland, v. 557$)^{56}$.

${ }^{53}$ Versos 241, 288, 292, 329, 364, 417, 743, 1373, 1846 et passim.

${ }^{54}$ Versos 889, 1347, 1669, 2027, 2049, 2543, 2559 et passim.

${ }^{55}$ Bédier ha hecho notar este fenómeno ya en la épica francesa (BÉDIER 1968, p. 302); pero hay que advertir, sin embargo, que cuando el fenómeno se llega a dar en la Chanson, es en el interior de un diálogo y no de un monólogo, lo que puede atribuirsele fácilmente a un copista distraído y no necesariamente a una intención estilística determinada.

${ }^{56}$ No descarto, no obstante, que este v. 409 pudiera ser un calco realiza- 
Lo to como pronombre posesivo no se repite; existe, sin embargo, lo so (vv. 977, 1326, 1557).

A Dios se acomendó: como verbo transitivo acomendar aparece en otras partes del poema (vv. 256, 372, 2154, 2628, etc.), siempre en el primer hemistiquio; como verbo reflexivo es una forma única.

Regularmente la forma ser pagado de (verbo activo o reflexivo en voz pasiva, que sirve para expresar un estado de contento) aparece siempre complementada por un pronombre demostrativo que introduce la preposición de; por ejemplo, Yo desso me pago, v. 141 (así, vv. 129, 146, 495, 826, 1296, 2462), y sólo una vez se menciona el complemento (Todos son pagados de las vistas, quantos que $i$ son, v. 2119). En el pasaje interpolado se utiliza la forma ser pagado de con un adverbio - la única vez-y explicitando el complemento.

\section{El Cuerpo del Delito}

El episodio interpolado abarcaría los vv. 404-412, según lo indican las series paralelas entre las que se ubica (los actuales vv. 376-395, 394-403 y 413-415), y se habría incluido en el cuerpo de lo que serían las actuales tiradas 18 y 20 , vv. 295-403 y 413415 , con asonante $-\hat{a}-(e)$. Muy posiblemente, la interpolación se habrá escrito por falta de espacio en algún margen o al pie del folio en que se copiaba, con lo que se explican las falsas asonancias y, especialmente, el adelantamiento del v. 408 en el inmediato anterior del manuscrito de Vivar.

La lengua del episodio, en su origen, podría difícilmente provenir de una tradición oral: el breve texto se acomoda mejor a una tradición letrada, como se observa al compararlo con las referencias literarias próximas que le hemos enfrentado. Estas coincidencias - en ocasiones ilustradas, bien es cierto, por textos posteriores pero que suponemos pertinentes como un muestreo panorámico y no como una búsqueda de fuentes - nos muestran una intervención en modo alguno improvisada, muy por el contrario: la responsable de este pasaje interpolado sería una mano meticulosa, sensible y conocedora del ethos literario de su tiempo que, ya por afán meramente estético, va por un interés propa-

do sobre el v. 925 del mismo poema, o viceversa. 
gandístico, ya por un proselitismo inmoderado, se habría atrevido a incursionar en el códice que copiaba.

Nuestra intención hasta aquí - será oportuno decirlo- no ha sido la de sugerir la fragmentariedad del corpus poético tal cual lo hemos recibido, como quisquillosos herederos, sino, por el contrario, subrayar tan oportuna y afortunada invención, que nos ha dotado de uno de los episodios más expresivos y - paradójicamente- humanos del poema.

\section{El LUGAR DEL CRIMEN: TRADICIÓN MANUSCRITA EN EL POEMA DH MO CD}

El códice único del PMC, tal y como hasta hoy se nos conserva, apunta por lo menos hacia la existencia de dos versiones manuscritas, no muy diferentes una de la otra: el apógrafo ${ }^{57}$ que lo preserva, datado hacia la primera mitad del siglo XIV.58 y un apógrafo modelo -o autógrafo ${ }^{59}$, según se lea el explicit copiado en el códice- sobre el cual se realizó la copia conservada, fechable a partir de los datos contenidos en una subscriptio copiata al final del texto (vv. 3731-3733): año 1245 era (1207 de la nuestra).

Jules Forrent ha intentado ya, con una perspectiva implícitamente conciliadora, fijar los estados de transmisión del poema durante el siglo $x 1^{6 \%}$ : sin embargo como él mismo aceptaha en

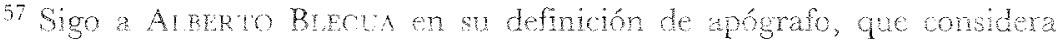
tanto "el manuscrito copiado sobre un autógrafo y que, a veces, suele llevar correcciones del propic autor" (1987, p. 40), como el "manuscrito que es co" pia de otro manuscrito perdido, original o copia" (ibid, p. 40, n. 5).

58 Menénidez Pidal, pp. 5-7 y n. 1; Horrent 1973, pp. 203-204; Michafi, pp. 55-56; Orduna 1989, pp. 6-7; Montaner, p. 77.

${ }^{59}$ Posición tomada por Colin Smith, quien considera el códice del siglo XIV como "una copia hecha probablemente a través de una serie de copias de un manuscrito original que Per Abbat escribió en 1207" (SMlTH, p. 110; también Smith 1983, pp. 106-107).

60 Horrent (1973, pp 243-311) reúne y articula - a partir de una serie de indicios mantenidos en el códice conservado- distintas tentativas de datación propuestas por otros críticos (Curtius, Ubieto, Menéndez Pidal, Russell, etc.) para constituir con ello una suerte de stemma codicum del Cantar en su transcurso por el siglo XII: la versión más antigua nacería hacia 1120, en la generación inmediata a la del Cid; una primera refundición entre 1140 y 1150 , se escribiría durante el reinado de Alfonso VII; una segunda refundición tendría lugar luego de 1160, conservada en un modelo de 1207 y transcrita por Per Abbat - que Horrent supone el amanuense del siglo XIV. Esta segunda refundición, de 1160 , sería el $P M C$ en un estado muy próximo al que 
el momento de su estudio (impreso por primera vez en 1964), "las condiciones presentes de la investigación no nos autorizan a remontarnos más allá de la versión poética que ha llegado hasta nosotros" "61.

¿Cuáles son esas mismas condiciones hoy dia? A la luz de nuevas investigaciones podemos, sobre bases sólidas, detallar al menos dos estados de transmisión del poema -apógrafos ambos, según ha podido demostrarse:

a) Por principio, el códice conservado: se trata de un códice de pergamino en cuarto, con 74 folios agrupados en once cuadernillos, escrito con letra gótica redonda libraria de mediados del siglo XIV? Esta copia es en general pulcra ${ }^{63}$ y realizada hasta con un chento tgrn flologicot.

b) $\mathrm{Y}$ un códice anterior, datado hacia principios del sigio xin, hipotético, que corresponde al modelo del cual se sirvio el copista del sigo XIV, $y$ que se indica en el explicit:

Quien escrivió este libro, idél' Dios paraíso, amén!

Per Abbat le escrivió en el mes de mayo

en era de mill $\tau$. C.C. xL.v. años (vv. 3731-3733)

Este explicit ha sido leído de varias maneras, según las cuales estaremos situados ante un modelo autógrafo o apógralo. Apoyando la primera opción, $\mathbf{C}$. Smith ${ }^{\mathrm{o}}$ desestima el papei de meru copista de Per Abbat y prefiere asignarle el de autor ${ }^{66}$ convirtiendo así el manucrito modelo en un autografo, a partir de la

se nos ha conservato.

${ }^{61}$ Horrent 1973, p. 298.

${ }^{62}$ Horrent 1973, pp. 203-204; Oriduna 1989, pp. 6-7. Pueden verse las descripciones de los últimos editores que han trabajado con el manuscrito de la Biblioteca Nacional (Menéndez PIDal, pp. 1-18; Michael, pp. 54-56; Montaner, pp. 76-78; con mes codiculogicos, ambín Orduna 1989).

63 "El texto del copista del siglo xiv es bastante correcto en general, aunque a veces sufre equivocaciones típicas del proceso de copia manuscrita" (MONTANer, p. 78).

${ }^{64}$ Orduna 1989, p. 8.

65 Smrth 1977, pp. 13 ss. y 63 ss.; Sмmtu 1983; Smrth, pp. 38 ss. Otros críticos también han admitido como posible la autoría de Per Abbat, con algunos matices: Criado de Val, Riaño Rodríguez y Ubieto Artet? (véase SchaFFER 1989, p. 128).

66 Ibid., pp. 113-116. 
significación de escriuió como "componer" 67 y de la identificación de un Per Abbat mencionado en un diploma falsificado en Palencia - conocido como el manuscrito "Apócrifo del Abad Lecenio" 68 - y que demuestra la presencia de un falsificador con "acceso a una colección de materiales cidianos - legales algunos, algunos literarios y quizá orales también, algunos quizá de origen monástico y del tipo que entró después a formar parte de la "Estoria del Cid o *Leyenda de Cardeña" 69.

Otros críticos y editores prefieren, sin embargo, mantener para el manuscrito de Per Abbat el título de apógrafo, mucho más seguro y conveniente si se tiene en cuenta los usos escriturarios de la época. Horrent explica el sentido de escriuió como "hacer las letras", "modelarlas"77, de acuerdo con el significado que el mismo poema le da a esta acción (por ejemplo, en los vv. $527,1259,1773,1956)$; hace notar, asimismo, el empleo particular que se hace de libro en el mencionado explicit, refiriéndose a la obra como objeto y no como materia épica (gesta, v. 1085; nuevas, v. 3729), obra poética (coplas, v. 2276) o texto en relación con su ejecución (cantar, v. 2276). "Así pues -concluye J. Horrent-, el llamado Per Abbat en el explicit no se presenta como poeta, sino como copista" 71 .

La fecha del explicit (era de mill $\tau$. C.C. xL.v. años, y 1207 de la nuestra) constituyó otro punto para el debate ${ }^{72}$ : demasiado temprana para corresponder con la datación del códice conservado, de mediados del siglo XIV, sugería ser el explicit de un mode-

${ }^{67}$ SMith 1977, pp. 17-20; SMith 1983, pp. 68-69; SMith, pp. 40-41. Véanse las conclusiones de Schaffer 1989 y de Michael 1991. (Por desgracia no he podido consultar este último en el momento de escribir el presente artículo.)

68 Hay una edición en Menéndez Pidal 1956, pp. 840-844.

${ }^{69}$ SmiTh 1977, p. 33. Las pesquisas de Smith sirvieron, sin duda, para demostrar lo factible que resultaba la sugerencia hecha por P. E. Russell en 1952 sobre un posible archivo cidiano, del que habría echado mano el autor del poema con el fin de construir un relato altamente verídico (Russell 1978 , p. 27), pero dejaban todavía sin justificar del todo la atribución de la autoría del poema a Per Abbat; como apuntaba Ian Michael "no obstante el gran interés de este documento, Smith no ha podido establecer un nexo entre este Per Abbat y el poema"' (Michael, p. 49, n. 60).

${ }^{70}$ Horrent 1973, p. 199.

${ }^{71}$ Ibid., p. 200; también Michael, p. 310, n.; Schaffer 1989; Michael 1991; Montaner, pp. 685-687.

72 Deyermond 1977, pp. 18-19. 
lo perdido ${ }^{73}$. Los primeros editores del $P M C$ acreditaron esta disparidad suponiendo la alteración intencional de la fecha en el manuscrito conservado: luego de las centenas, se observa un pequeño espacio que podría muy bien ser el de una $C$., raspada con el propósito, ya de envejecer el códice ${ }^{74}$, ya de subsanar un error del copista del siglo XIV que habría escrito inconscientemente la fecha correspondiente a su época y no a la del modelo ${ }^{75}$.

No es sino a partir de fechas muy recientes que Alberto Montaner ha podido dar una respuesta confiable a dicho desacuerdo, sometiendo el explicit del códice conservado a un minucioso trabajo de inspección ${ }^{76}$. El manuscrito muestra, en el espacio entre la segunda $C$. y la $x$, tres pequeñas incisiones dispuestas respectivamente en forma venical, dagonal y vertical, la presencia de esta imperfección del pergamino garantiza que no se hizo ninguna raspadura en el lugar - en cuyo caso, la superficie se mostraría uniformemente escoriada como sucede en otras borraduras del códice. Demasiado cortas y demasiado separadas para significar por sí mismas una raspadura, el espacio demuestra no haber sido borrado nunca. Junto a esta evidencia, el no haber detectado rastros de tinta en la minuciosa inspección, aseguran que la fecha en el explicit del códice del siglo XIv nunca fue alterada - ni escrita, ni borrada ${ }^{77}$.

Sus conclusiones, pues, nos permiten utilizar la fecha de 1207 como el teminus ante quem para la composición del poema, y determinar el valor de dicha nota:

Como dicha fecha no se corresponde con la época del códice, se ha de admitir que se trata de una subscriptio copiata, es decir, de una transcripción literal del colofón original de su modelo: un manuscrito de principios del siglo xir realizado por el copista Per Abbat ${ }^{78}$.

${ }^{73}$ Michael, pp. 56 y $310, \mathrm{n}$.

74. Bello 1881, pp. 2-3; Menéndez Pidal, pp. 13 y 18.

75 J. Horrent 1973, pp. 198 ss.; HorRENT, pp. viii-ix. Para un resumen de la cuestión, Schaffer 1989, pp. 118-120.

${ }^{76}$ Se ha servido de una lámpara de luz ultravioleta, de una lámpara de reflectografía infrarroja y de un video microscopio de superficie durante los dias 2 y 31 de julio de 1992 para dicha revisión; véase la nota que a propósito escribe Montaner en su edición (pp. 687-688, n.); asimismo, "M.t.C.C. xL.v años: un análisis microscópico" [en curso de publicación].

77 MONTAner, pp. 687-688, n.

78 Ibid., pp. 77-78. 
Lo anterior nos brinda bases sólidas para bosquejar un estado hipotético del $P M C$, anterior a la copia conservada.

Este modelo del siglo xuI, según lo indican muchos de los yerros - y consecuentemente, muchas de las comiendas-... pre. sentes en el códice del siglo XIV, debió haber sido escrito y no producto de la recitación juglaresca ${ }^{79}$. Como ya Menéndez Pidal hacía notar, en nuestro manuscrito conservado ". . . hay ciertas erratas en la copia de Per Abbat que no pueden provenir de mal oído, sino de mala interpretación de un original escrito; $v$ gr, atineza, de atieza, por Atienza; y Deyna, de Deia, por Denia''so. Muchos son los descuidos que podemos advertir en el apógrafo del siglo xiv gue hacen conchir esto: dislocación de versos ${ }^{81}$, la

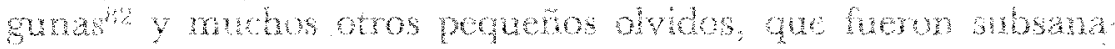
dos en waras ocustones sum thea.

In el f. 9x, que contiene al episodio interpolado, en espe cial, encontramos yerros que aluden expresamente a una fuente escrita:

1) Primer verso del f. 9r (cito por la ed. facs.; v. 398 de las eds. crits.), donde aparece torres tenemos:

De dieftro alilon las [tachado: tra $\uparrow=$ tierras / supra linea: torres] $\bar{q}$ moros las han

El error entre therras $(=t r a i)$ y tomes, como podenos adver tir, no pudo haberse originado por una confusión al momento de atender nuestro copista a un dictado o recitado (fuese que se le dictara un texto previanente escrito, cono cra uso frecuchte, o se le recitara el poena de memoria); dificimente podremos re. presentamos la diptongación en ie de una vocal tónica como o. Sucedería, pues, que al leer *torres, escrito muy posiblemente como *tores o *toRes, grafías con las que se indicaba rambién la $r$ vibrante múltiple, nuestro copista habría cometido una lectio facilior: tral (= tierras), que era una abreviatura frecuente hacia

79 Así pensaba, por ejemplo, DeYermond 1965.

80 Menḱmocz Phai, p. 29. Walsh acepta esto mismo, aunque detrás de la copia conservada observa huellas de un primer estado de transmisión oral o memorística (WALSH 1990, p. 4).

81 Por ejemplo, vv. 394.395; v. 1086 para algunos editores, que lo colocan luego del 1084; vv. 1145-1156; vv. 1584-1590; vv. 1688-1689; vv. 25222523 , colocados a continuación del 2530 , etcétera.

${ }^{82}$ Así lo advierten, por ejemplo, entre el v. 181 y el siguiente alguxos de los editores; luego del v. 876, una laguna sugerida por el uso de aquesta. 
finales del siglo $\mathrm{XII}^{83}$. La enmienda, de manos del primer corrector, está hecha también a partir de un texto escrito, y prefirió al hacerla desatar las abreviaturas escribiendo torres sobre la línea.

2) En el v. 8 del mismo folio (v. 405 de las eds. crits.), hay otra corrección importante:

[vn: corrección sobre: $Y /$ supra linea: $n]$ fuenol $p$ ' adurmjó

el copista comete una duplografia al repetir el adverbio $Y$ del verso precedente en el v. 405, quedando entonces $Y$ fuenol $p$ ' $6 . .$. , forma habimente corregida luego por el primer corrector con el homado del trazo infrior de la $Y$ y la adion de una $n$ voladia. Esta útima enmienda, como puede argumentarse, no tuvo necesidad de recurrir a una fuente escrita, y pudo realizarse más por sentido común que por apego al modelo que se copiaba; el error, sin embargo, difícilmente pudo tener su origen en la recitación de un juglar o en el dictado del texto: el copista, como a menudo sucedía, mantuvo la imagen gráfica del verso procedente en su modelo, reproduciéndola de manera inconsciente en su copia.

El modelo del manuscrito del siglo XIV sería un modelo escrito, lo que concuerda con la conservación del colofón original de $1207^{84}$ y con los datos contenidos en éste: la mención material de libro (v. 3731), en el sentido de "manuscrito"35, por un lado; por otro, la doble indicación de haber sido escrito (escriuió, vv. $3731-3732)$

Podemos, pues, considerar con un amplio margen de certeza el empleo de una fuente escrita en la factura del códice conservado. Conviene ahora preguntarse si con igual seguridad podríamos afirmar que el manuscrito que en ese momento se tenía como modelo para el códice del siglo xIV era el escrito por Per Abbat hacia principios del siglo XIII ${ }^{86}$.

${ }^{83}$ Pueden verse varios ejemplos en documentos castellanos de finales del siglo Xil en la Cres. Esp. Med., pp. 56-60.

84 Montaner, pp. 77-78 y 687-688, n.

${ }^{85}$ Horrent 1973, p. 199; Schaffer 1989, pp. 136 ss.

86 C. Smitu pensaba (en 1984) que el apógrafo del siglo Xiv provenía de "... una serie de copias de un manuscrito original que Per Abbat escribió en 1207' (Sмiтh, p. 110; Sмiтн 1983, p. 107). En 1979 suponía, sin embargo, que la copia conservada representaba fielmente el estado en que Per Abbat había dejado la copia de 1207 (SMITH 1979), como más adelante se comenta. 
Menéndez Pidal, atendiendo a la conservación de los arcaísmos presentes en el poema, prefiere suponer un reducido número de copias (dos, que en su caso son anteriores al códice conservado, y en el nuestro corresponderían a la copia realizada por Per Abbat y a un manuscrito anterior), lo suficientemente fieles como para mantener, por ejemplo, asonantes ya envejecidos para el siglo XIV ${ }^{87}$. Smith, en 1979 , pensaba también en una tradición conservadora: atendiendo a los folios faltames en el manuscrito del siglo XIV, concluía "...que la copia que conocemos, de mediados del siglo xIV, representa con bastante fidelidad la obra tal como la dejó Per Abad en 1207. .,"88.

Creo que la opinión general apunta hacia un manuscrito conservador, lo que obliga a pensar en un corta tradición manuscrita: muy pocas serían las copias intermediarias que podemos suponer entre el modelo hipotético de 1207 y el códice de Vivar; el mantenimiento del explicit de 1207 en el apógrafo de mediados del siglo XIV nos aconseja, incluso, suponer la falta total de intermediarios. Las suscripciones de los modelos solían copiarse en los scriptoria para documentar - a modo de registro- la procedencia de los textos. La presencia del colofón en el apógrafo del siglo XIV estaría indicando la procedencia del manuscrito que se copiaba en ese momento: el "libro" que Per Abbat debió escribir -escriuió- hacia 1207. Así, enfrentaríamos un modelo con su copia, provenientes ambos de una misma rama de la tradición manuscrita del códice de Vivar.

Con estos datos a la mano, la interpolación de los vv. 404-412 debió terier su origen en alguno de los dos apógrafos que nos son conocidos, posibilidad que automáticamente elimina al códice conservado $^{89}$. Podemos así, con un margen amplio de probabilidades brindado por el camino documental del $P M C$ que hemos trazado, precisar el espacio en que tuvo lugar esta interpolación: sobre un modelo anterior a la versión hipotética de 1207 , escrito al parecer - posiblemente dictado, lo cual dudamos-, Per Abbat habría incurrido en interpolar, ya por el mal estado de su modelo, ya por causas azarosas que difícilmente llegaremos a concretar, ciertos pasajes que nos fueron conservados en el ma-

${ }^{87}$ Menéndez Pidal, pp. 32-33.

${ }^{88}$ SMITH 1979 , p. 36.

${ }^{89}$ Las prosificaciones describen ya el episodio para finales del siglo XIII (por ejemplo, la $P C G$, de 1289); por otro lado, el manuscrito evidencia una serie de marcas que no nos permiten pensar en una composición espontánea (recuérdense los errores comentados en el f. 9r, por ejemplo). 
nuscrito perdido de 1207 y en el códice del siglo XIV - especialmente, el episodio de los vv. 404-412 de que hemos venido hablando.

¿Qué particularidades tendría este modelo, anterior a 1207 ? Varios indicios apuntan hacia la caracterización nebulosa de este primer estado conjetural del poema. Se trataría, por principio, de un texto manuscrito, según sugieren ciertos indicios en el códice conservado: la homegeneidad evidente que se muestra en el usus scribendi del modelo anterior a 1207 cuando se le compara con la intervención que supongo de esta fecha, obliga a pensar en un modelo escrito. Un Per Abbat, en el mes de mayo de 1207 - si hemos de creer a pies juntillas en los datos de la suscripdión-, hos entregaba una copla que sufrió algunas intervenciones de su propia mano, no tan importantes ni tan numerosas que bastaran para refundir por completo el cantar. Por más modernizaciones y licencias que haya, el papel de un copista no consistía en refundir y remozar el texto a su gusto -o a las necesidades de un nuevo público, como toca a los cantores serbo-croatas estudiados por Parry y Lord-, sino en copiarlo con apego riguroso: las intervenciones, pues, vendrían a significar un rasgo de buena voluntad del copista ante alguna laguna, algún pasaje incomprensible, un pergamino deteriorado, algún folio perdido, etc. La uniformidad del modelo empleado por Per Abbat apunta hacia un texto fijado previamente por escrito. Las escasas inconsistencias en el argumento del poema ${ }^{90}-\mathrm{y}$ frecuentes en la poesía oral ${ }^{91}$-; la pervivencia de una veintena de nombres asociados a la leyenda cidiana ${ }^{92}$, son también indicios que nos llevan a pensar en una fuente escrita para el modelo que copiaba Per Abbat.

Esta versión - autógrafo o apógrafo, no sabemos- no podría datarse con demasiada anterioridad a la fecha de su copia, y creo coincidiría con la fechación que ya muchos críticos adelantaban para un ejemplar temprano del poema. Bello se refería “. . a la primera mitad del siglo XIII, aunque con más inmediación al año 1200 de la era vulgar que al año 1250" "93; a media-

${ }^{90}$ La reaparición del Albar Salvadórez (v. 1994), luego de haber caído prisionero de Yúcef. (v. 1681); la cofia del Cid, de escarín en el v. 3094, de rrançal en 3493, etc. Véase Menéndez Pidal 1963, pp. 49-51.

91 Éstas, en especial, hacían suponer a Deyermond que "... while the Per Abbat manuscript seems fairly close to a dictated oral text, its ancestry may not be wholly oral"' (DEYERMOND 1965, p. 2).

${ }^{92}$ Sмітн 1977, pp. 55-56.

93 BeLlo 1881, p. 15; también p. 20. 
dos ya de nuestro siglo, la fecha propuesta por Menéndez Pidal (1140) tiende a adelantarse: basándose en criterios estilísticos, E. R. Curtius fechaba el poema con posterioridad a $1180^{94}$; P. E. Russell, estudiando la relación del poema con los documentos diplomáticos de la época, databa el cantar hacia los últimos treinta años del siglo xII ${ }^{95}$; J. Horrent publica posteriormente (1964) una crítica sistemática a las últimas opiniones de Menéndez Pidal, y entre los varios estados de redacción que le supone al poema, se inclina por una versión posterior a 1160, realizada durante el reinado de Alfonso VIII ${ }^{96}$. Basándose en el trasfondo ideológico que se permea en el cantar, María Eugenia Lacarra pensaba también en una fecha "hacia finales del siglo xir o prin" cipios del xm" A7. Aberto Montaner concluye esto mismo, aten" diendo a la consticución social rellejada on el poemas ${ }^{96}$. A partir de dichas investigaciones, y también desde otras perspectivas ${ }^{99}$, una fecha tardía parece la opinión más generalizada.

Así pues, a la luz de nuestras conclusiones podemos aventurar un posible stemma codicum que describa - dentro del marco de una síntesis metodológica, y de acuerdo con el estado actual de nuestras investigaciones - la tradición escrita del poema:

a) Una primera versión del poema, manuscrita, de finales del siglo XII - presumiblemente, los últimos treinta años-, autógrafa o apógrafa y, hasta el momento, hipotética.

b) Una segunda versión manuscrita de 1207, remozados y quizá también modernizados algunos aspectos, alterados algunos pasajes -especialmente, hemos referido la inter polación de los vv. 404-412--, no suficientes para, por sí solos, alterar - refundir, por cuanto hace a las características de un determinado usus scribendi- el códice modelo;

94 Curtius 1949; véase la respuesta de Menéndez Pidal en 1963, pp. 97-105.

95 Russell 1978, p. 21.

96 Horrent 1973, pp. 310-311; también, 252 ss.

97 LACARRA 1980 , pp. $222 \cdots 254$.

98 Montaner, p. 8 y n. 6.

99 Gicovate 1956, lo hace a partir de una interpretación del v. 3724; UвIETo 1957, trabaja alrededor de varios puntos, tanto léxicos como históricos; Sмгтн 1977, pp. 35-62, hace notar las graves faltas entre la realidad histórica y la ficción poética (en un estilo muy cercano al de BeLLo 1881, pp. 15-16). Pattison 1967 y 1985 lo hace desde criterios lingüísticos. Deyermond, en 1971, es el primero en considerar esta fechación tardía dentro de un compendio histórico de literatura medieval española (Dexermond 1976, pp. 91-92). 
versión hipotética también, sugerida por el colofón copiado en el manuscrito del siglo XIV.

c) Finalmente, una copia con letra del siglo XIV, en 40,74 ff., actualmente conservada en los fondos de la Biblioteca Nacional de Madrid (signatura vitra. 7-17) ${ }^{100}$.

Alejandro Higashi

Universidad Veracruzana

\section{BIBLIOGRAFIA}

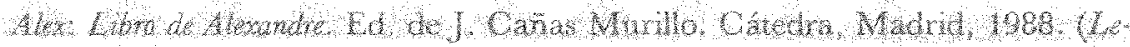
tras hopantas, 200)

Alonso, Damaso 1973. "Estilo y creación en el Poema del Cid", en Obras completus. Gredos, Madrid, t. 2, pp. 107-143.

BEDIER, JOSEPY 1968. La Chanson de Roland commeniée par... L'édition d'art H. Piazza, Paris.

Bello, Andrés 1881. "Prólogo", en Obras completas. Consejo de Instrucción Pública, Santiago de Chile, t. 2, pp. 1-30.

Blecua, Alberto 1987. Manual de crítica textual. Castalia, Madrid. (Literatura y sociedad, 33).

Bustos Tovar, J.J. de (ed.), Poema de mio Cid. Alianza, Madrid, 1983 (Clásicos, 981). También Alce, Madrid. (Clásicos Alce, 1).

Cancionero de Ripoll: Cancionero de Ripoll. Ed. de J. L. Moralejo. Bosch, Barcelona, 1986.

Casalduero, Joaquín 1967. "El Cid echado de tierra", en Estudios de literatura española. Gredos, Madrid, pp. 27-54. (Bibi. Rom. Hisp., Estudios y ensayos, 54).

Caspro, Americo 1960. "Poesía y realidad en el Poema del Cid", en Hacia Ceroantes. Taurus, Madrid, pp. 37-51.

Cátedra, Pedro M. (ed.), Poema de mio Cid. Planeta, Barcelona, 1985 (Clásicos Universales Planeta, 100).

Chanson: La Chanson de Roland. Ed. de J. Bédier. H. Piazza, Paris, 1974.

Chasca, Edmund de 1972. El arte juglaresco en el "CMC". Gredos, Madrid. (Bibl. Rom. Hisp., Estudios y ensayos, 101).

100 Vaya en prenda mi gratitud para todos aquellos amigos que de una u otra manera fueron partícipes de mi entusiasmo en la empresa; agradezco, muy especialmente, a Laurette Godinas (Université de Liège) por su invaluable y afectuosa colaboración; a Margit Frenk (Instituto de Investigaciones Filológicas de la UNAM) y a Manuel Sol (Universidad Veracruzana) por la lectura atenta de una primera versión, sensiblemente más extensa, del presente trabajo. A Lillian von der Walde y a José Luis M. Suárez, por su interés siempre manifiesto. 
Crest. Esp. Med.: Crestomatía del español medieval. 2 ts. Ed. de R. Menéndez Pidal. Seminario Menéndez Pidal-Gredos, Madrid, 1982.

Gurtius, E. R. 1949. "Antike Rhetorik und vergleichende Literaturwissenschaft", $C L, 1,27-31$.

- 1975. Literatura europea y Edad Media latina. 2 ts. Trads. M. Frenk y A. Alatorre. F.G.E., México.

DCECH: J. Corominas, y J. A. Pascual, Diccionario crítico etimológico castellano e hispánico. 5 ts. Gredos, Madrid, 1980. (Bibl. Rom. Hisp., Diccionarios, 7).

De divinatione: Marco Tulio Cicerón, De la adivinación. Trad. J. Pimentel Álvarez. UNAM, México, 1988

Deyermond, A. D. 1965. "The singer of tales and Medieval Spanish epic", $B H S, 42,1-8$.

- 1976. Hestoria do la litoratsra estanola de la Edad Modia. Ariel Barcelona. (Leives e cleter, 1).

- 1977. "Tendences in MC scholarship, 1943.73", ch Mio Cid Sudies. Ed. A. D. Deyemond. Tamesis Books, London, pp. $13-47$.

— 1987. El Cantar de Mio Cid y la épica medieval española. Sirmio, Barcelona. (Biblioteca General, 2).

Dunn, P. E. 1962. "Theme and myth in the PMC', Ro, 83, 348-369.

FaulHaber, C. B. 1976. "Neo-traditionalism, formulism, individualism, and recents studies on the Spanish epic", $R P h, 30,83-101$.

Garai-Gómez, Miguel (ed.), Cantar de mio Cid. Cupsa, Madrid, 1977. (Hispánicos Universales, 9).

— 1975. "Mio Cid". Estudios de endocrítica. Planeta, Barcelona. (Ensayos, 44).

Gicovate, B. 1956. "La fecha de composición del $P M C$ ", H, 39, 419-422.

HATHAWAY, R. L. 1974. "The art of the epic epithets in the Cantar de Mio Cid"', HR, 42, 311-321.

Herennius: Rhétorique à Herennius. Ed. de G. Achard. Les Belles Lettres, Paris, 1989.

Horrent, Jules (ed.), Cantar de mio Cid, Chanson de mon Cid. 2 ts. E. Storyscieta, Gante, 1982.

- 1973. Historia y poesía en torno al "Cantar del Cid". Ariel, Barcelona. (Letras e ideas, Maior, 2).

— 1978. "Observations textuelles sur une édition récente du $C M C$ ", $L R$, $32,3-51$.

Johnston, R. M. 1984. "The function of laisse divisions in the PMC", $J H P h, 8,185-208$.

Lacarra, María Eugenia 1980. El Poema de mio Cid: realidad hiśónica e ideologia. José Porrúa Turanzas, Madrid.

Lázaro Carreter, Fernando 1973. Diccionario de términos filológicos. Gredos, Madrid. (Bibl. Hisp. Rom., 'Manuales, 6).

LBA: Arcipreste de Hita, Libro de buen amor. 2 ts. Ed. de J. Joset. EspasaCalpe, Madrid, 1974. (Clás. Castellanos, 14 y 17).

López Estrada, F. 1982. Panorama crítico sobre el "PMC". Castalia, Madrid. (Literatura y sociedad, 30 ).

Menéndez Pidal, Ramón (ed.), Cantar de mio Cid. Texto, gramática y vocabulario. 3 ts. Bailly-Baillière e hijos, Madrid, 1908-1911. Ed. rev. en Obras de 
Ramón Menéndez Pidal. Espasa-Calpe, Madrid, 1944-1946, ts. 3-5.

1949. Poesía juglaresca y juglares. Espasa-Calpe, Buenos Aires. (Austral, $300)$.

- 1956. La España del Cid. 2 ts. Espasa-Calpe, Madrid.

— 1963. En torno al "Poema del Cid". E.D.H.A.S.A., Barcelona.

MérimÉE, E. [1915]. "Introduction", en Le poème du Cid. Extraits. La Renaissance du Livre, Paris.

Michael, Ian (ed.), The Poem of the Cid: A new critical edition of the Spanish text. With an introduction and notes by Ian Michael. Together with a new prose translation by Rita Hamilton and Janet Perry. Manchester University Press, Manchester, 1975. También Penguin Books, London, 1984. Tr. esp. Castalia, Madrid, 1976. (Clás. Castalia, 75). Ed. rev. 1978 [cito por esta última].

- 1991. "Per Abbat, cautor o copista? Enfoque de la cuestión", en Homenaje a Alonso Zamora Vicente. Castalia, Madrid, t. 3, pp. 179-205.

Ailes gloriosus: Pisuio, El miltar fanfarrón. Trad. de J. i. Ciruelo. Bosch, Barcelona, 1975.

Milgr: Gonzalo de Berceo, Milagros de Nuestra Señora. Ed. de M. Gerli. REI, México, 1990. (Letras Hispánicas, 224).

Mio Cid Studies: Mio Cid Studies. Ed. A. D. Deyermond. Tamesis Books, London, 1977.

Montaner, Alberto (ed.), Cantar de mio Cid. Crítica, Barcelona, 1993. (Biblioteca clásica, 1).

Montgomery, T. 1977. "The PMC: Oral art in transition" en Mio Cid Studies. Pp. 91-113.

- 1984. "Mythopoeia and myopia: Colin Smith's The making of the PMC", JHPh, 8, 7-16.

MyERS, O. T. 1977. "Multiple authorship of the PMC: A final word?", en Mio Cid Studies. Pp. 113-127.

Orduna, G. 1989. "El testimonio del códice de Vivar", Incipit, 9, 1-12.

PatTison, D. G. 1967. "The date of the CMC: A linguistic approach", MLR, 62, 443-450.

1985. "Word formation in the PMC: A second visit", LCo, 14, 86-88.

PCG: Primera Crónica General de España. Ed. de R. Menéndez Pidal. Gredos, Madrid, 1955.

PFGz: Poema de Fernán González. Ed. de A. Zamora Vicente. Espasa-Calpe, Madrid, 1970. (Clás. Castellanos, 128).

Poema de mio Cid. Edición facsímil del Códice de Per Abat, conservado en la Biblioteca Nacional. Hauser y Menet para la Dirección General de Archivos y Bibliotecas, Madrid, 1961.

Poema de mio Cid. 2 ts. Excmo. Ayuntamiento de Burgos, Burgos, 1982.

Richthofen, Erich von 1970. Nuevos estudios épicos medievales. Gredos, Madrid. (Bibl. Hisp. Rom., Estudios y Ensayos, 138).

Rico, F. 1993. "Un canto de frontera: "La gesta de mio Cid el de Bivar»", en Montaner. Pp. ix-xliii.

Roncaglia, Aurelio 1975. Principi e applicazioni di critica testuale. Univesità degli Studi di Roma-Bulzoni Editore, Roma.

Russell, P. E. 1978. Temas de "La Celestina" y otros estudios: Del "Cid" al "Quijote". Ariel, Barcelona. (Letras e ideas, Maior, 14). 
Salinas, Pedro 1958. "El Cantar de mio Cid. Poema de la honra", en Ensayos de literatura hispánica (del Cantar de mio Cid a García Lorca). Aguilar, Madrid, pp. 27-44.

Schaffer, M. E. 1989. "Poema or Cantar de Mio Cid: More on the Explicit", $R P h, 43,113-153$.

Sendebar: Sendebar. Ed. de M. J. Lacarra. Cátedra, Madrid, 1989. (Letras Hispánicas, 304).

Setenario: Alfonso el Sabio, Setenario. Ed. de K. H. Vanderford. Instituto de Filología, Buenos Aires, 1945. [Reimpr. Crítica, Barcelona, 1984].

Smith, Colin C. (ed.), Poema de mio Cid. Clarendon Press, Oxford, 1972. Trad. esp. Cátedra, Madrid, 1976. (Letras hispánicas, 35). Ed. rev. 1985 [cito por esta última].

- 1977. Estudios cidianos. Cupsa, Madrid. 1979... "La métrica del PMC: nuevas posibilidades", NRFH, 28, 30.56. 1983 . The mokn of he "PMC? Cambridge Unyersity Presk Cam bridge -

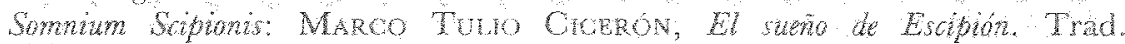
R. Acuña. UNAM, México, 1989. (Cuadernos del Centro de Estudios Clási$\cos , 29)$.

Sta. Or.: Gonzalo de Berceo, Poema de Sania Oria. Ed. de I. Uría Maqua. Castalia, Madrid, 1981.

Sto. Dom.: Gonzalo de Berceo, Vida de Santo Domingo de Silos. Ed. de T. Labarta de Chaves. Castalia, Madrid, 1973. (Clás. Castalia, 99).

Suárez García, J. L. 1990. "Hacia una bibliografía del PMC (1981-1988)", $L C O, 19,67-82$.

UBIET⿱㇒, A. 1957. "Observaciones al CMC", $A r b, 37,145-170$.

Vulgata: Biblia Sacra Vulgatae Editionis Sixti V et Clementis VIII, pont. max., auctoriiale recogtita. Gawhier Frater et Socii, Paris, 1837.

WaLsh, J. K. 1990. "Performance in the Poema de mio Cid", RPh, 44, 1-25.

West, G. 1983. "Hero or saint? Hagiographic elements in the life of Cid", JHPh, 7, 87-105. 